\title{
Meta-analysis of the differentially expressed microRNA profiles in nasopharyngeal carcinoma
}

\author{
Junwen Luan ${ }^{1}$, Junfu Wang ${ }^{1}$, Qinghong Su${ }^{1}$, Xuemei Chen ${ }^{2}$, Guosheng Jiang ${ }^{1}$, \\ Xiaoqun $\mathbf{X u}^{1}$ \\ ${ }^{1}$ Institute of Basic Medicine, Shandong Academy of Medical Sciences, Jinan, Shandong 250062, China \\ ${ }^{2}$ Department of Otolaryngology, The Second Hospital of Shandong University, Jinan, Shandong 250033, China \\ Correspondence to: Xiaoqun Xu, e-mail: xuxiaoqunsd@163.com \\ Guosheng Jiang, e-mail: jiangguosh@163.com
}

Keywords: nasopharyngeal carcinoma, miRNA, profiling, roubust rank aggregation method, meta-analysis

Received: July 02, 2015

Accepted: January 01, 2016

Published: January 25, 2016

\begin{abstract}
MicroRNAs(miRNAs), as non-coding molecules, were proved to be correlated with gene expression in naspharyngeal carcinoma (NPC) development. In this research, a comprehensive meta-analysis of eight independent miRNA expression studies in NPC was preformed by using robust rank aggregation method (RRA), which contained a total of 775 tumor and 227 non-cancerous samples. There were 7 significant dysregulated miRNAs identified including three increased (miR-483-5p, miR-29c-3p and miR-205-5p) and four decreased (miR-29b-3p, let-7d-5p, miR-100-5p and let7g-5p) miRNAs. Subsequently, the miRNA target prediction and pathway enrichment analysis were carried out to find out the biological and functional relevant genes involved in the meta-signature miRNA regulation. Finally, several signaling and cancer pathogenesis pathways were suggested to be more frequently associated with the progression of NPC. In this research the meta-signature miRNA identified may be used to develop a series of diagnostic and prognostic biomarkers for NPC that serve specificity for use in clinics.
\end{abstract}

\section{INTRODUCTION}

Nasopharyngeal carcionma (NPC) is one of the most malignant head and neck carcinoma [1]. There were more than 50 thousand deaths worldwide each year, most of which occurred in Asia including China, India, Thailand etc, while only a few cases were reported in Europe and the USA [2]. Despite therapeutic improvements in NPC treatment, low survival is due to late diagnosis, poor prognosis, and metastasis. Thus, it is of great importance to explore novel diagnostics and therapeutics for patients with NPC.

MiRNAs are a novel class of endogenous, short noncoding and single-stranded molecules, which range from 18 to 24 nucleotides, and play key roles in translation and expression of genes through binding to the 3 'untranslated region (3'UTR) of mRNAs $[3,4]$. To date, there has been increasing researches indicating that miRNAs are potential biomarkers in the diagnosis, therapy and prognosis of many kinds of tumours [5-8]. MiRNA microarray chip and re-sequencing technology have been broadly applied to identify the differentially expressed profiles between normal and nasopharyngeal carcinoma tissues in more and more researches [9-11]. Large number of differentially dysregulated miRNAs were found out in these profiling studies, however there is no consistant results among these researchs. Maybe it is confined to the diversity of highthroughput technology platforms, limited sample size, inconsistent annotation and increasing discovery of new miRNAs $[12,13]$.

A meta-analysis of dysregulated miRNAs expression in nasopharyngeal carcinoma was performed to overcome the limitations in these miRNA expression profiling studies. The robust rank aggregation (RRA) method followed by pathway analysis was applied in this research to find the key miRNAs in nasopharyngeal cancer and corresponding pathways [14]. Several crucial miRNAs target genes were predicted through bioinformatics tools, and then consensus targets were combined for further analysis in corresponding database, such as KEGG database, GO database and etc. This analysis could give us a new insight into the different expressed miRNAs profiling studies of nasopharyngeal carcinoma. Our work focused on identifying the consistence of 
differently expressed miRNAs, which is of great value in improving the diagnostics, therapeutics and prognosis in nasopharyngeal carcinoma.

\section{RESULTS}

\section{Study selection and data extraction}

Through the database retrieval, a total of 213 possible relevant studies were found according to the criteria. After carefully screened according to the criteria, the duplicated studies and reviews were excluded. There were only 8 studies used for the meta-analysis (Figure 1). All these studies were published between 2008 and 2015, most of which came from the region of East Asia. The average number of miRNA probes was up to 1221 (ranging from 207 to 2047) included in these studies with various profiling platforms. A total of 775 tumour and 227 noncancerous samples were used for meta-analysis. The major important information of these studies was recorded in Table 1. There were 238 differently expressed miRNAs reported in the 8 researches in total, out of which 114 were reported as increased expression of miRNAs, and 124 were decreased.

\section{Nasopharyngeal cancer miRNA meta-signature}

A meta-signature of seven dysregulated miRNAs was significantly identified with three increased and four

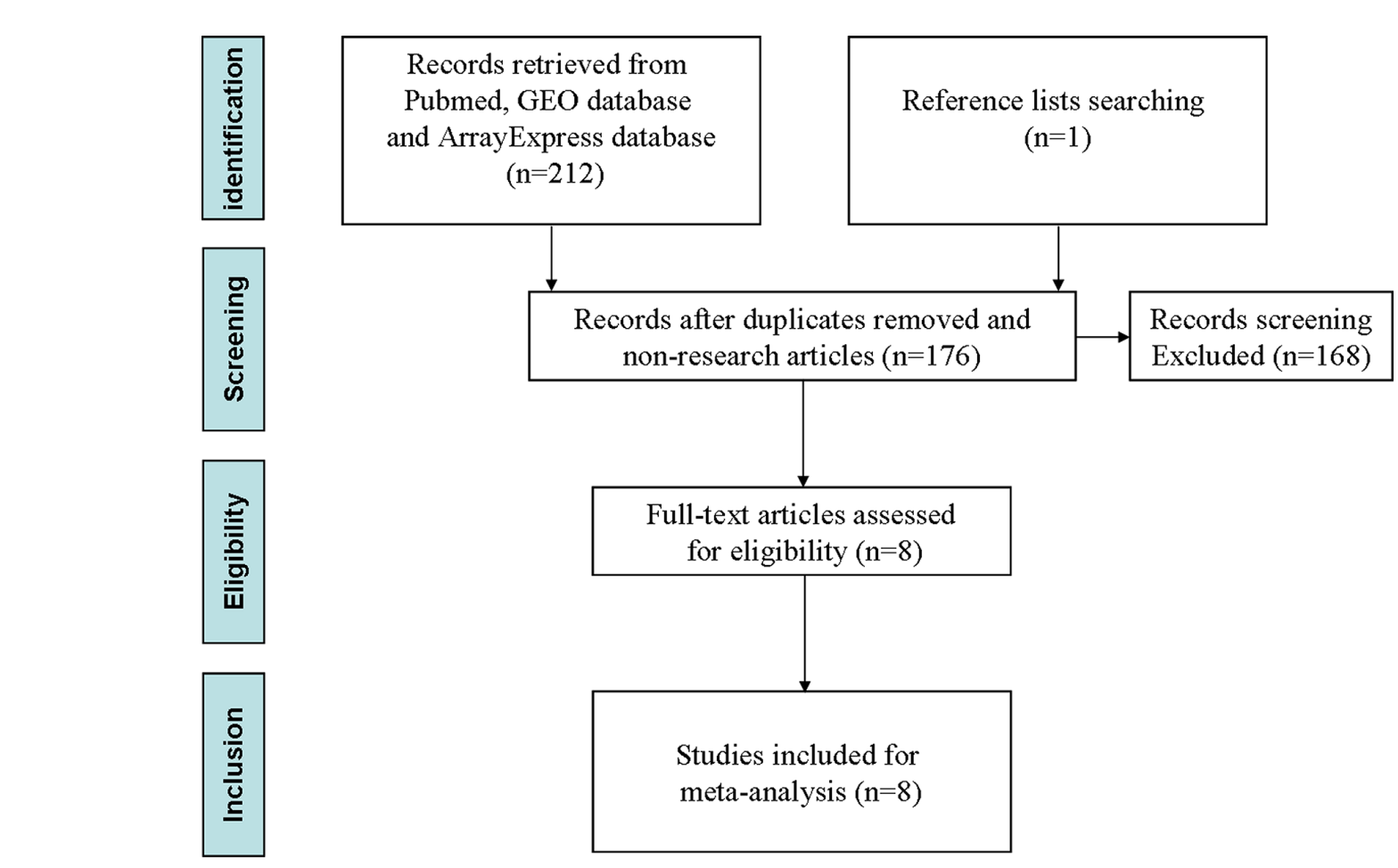
chromosomal locations. decreased in nasopharyngeal cancer samples compared to noncancerous nasopharyngeal tissues according to the permutation $p$-value. Only the miRNAs were reported that were detected at least three datasets by using robust rank aggregation (Table 2). The most significantly dysregulated miRNAs were miR-483-5p and miR-29b-3p, which were reported by three and five datasets, respectively. In addition, the $p$-values of other two increased miRNAs (miR-29c-3p and miR-205-5p) and three decreased miRNAs (let-7d-5p, miR-100-5p and let-7g-5p) were also less than 0.05 . But after Bonferroni correction, none of the meta-signature miRNAs reached the statistical significance in our research.

Three miRNAs, miR-29b-3p, miR-29c-3p, miR205-5p came from one cluster located at 1q32.2, and the cluster was found at MirBase within a distance less than $10 \mathrm{~kb}$. Other miRNAs were scattered on different

\section{The target prediction of meta-signature miRNAs}

The numbers of target counts were presented in Figure 2. The overlapping consensus targets of metasignature miRNAs identified by the robust rank aggregation were extracted, and predicted by at least two different algorithms and validated by two experimental databases (TarBase and StarBase). MiR-29b-3p and miR-29c-3p have more targets than others, while miR-483-5p has no targets, as there are no overlapping targets through the prediction.

Figure 1: Flow diagram of selection strategy. 
Table 1: Summary of eight independent NPC miRNA profiling studies

\begin{tabular}{|c|c|c|c|c|c|c|c|}
\hline \multirow[t]{2}{*}{ Study } & \multirow[t]{2}{*}{ Platform } & \multirow[t]{2}{*}{ Region } & \multirow{2}{*}{$\begin{array}{l}\text { Probes } \\
\text { of } \\
\text { miRNA }\end{array}$} & \multirow[t]{2}{*}{$\begin{array}{l}\text { Type of } \\
\text { samples }\end{array}$} & \multicolumn{2}{|c|}{ sample } & \multirow[t]{2}{*}{ Cut-off criteria } \\
\hline & & & & & Tumor & Control & \\
\hline Jordan 2014 [45] & $\begin{array}{l}\text { miRNA } \\
\text { microarry }\end{array}$ & $\begin{array}{l}\text { Washington, } \\
\text { DC USA }\end{array}$ & 1368 & tissues & $4 \mathrm{TT}$ & $4 \mathrm{NT}$ & $\mathrm{FC}>2, P<0.05$ \\
\hline Li $2011[11]$ & $\begin{array}{l}\text { Illumina } \\
\text { human } \\
\text { v1 mirnA } \\
\text { panel(Illumina) }\end{array}$ & $\begin{array}{l}\text { Nanning, } \\
\text { PR China }\end{array}$ & 735 & tissues & $8 \mathrm{TT}$ & $4 \mathrm{NT}$ & $\mathrm{SAM}, \mathrm{q} \leq 0.05$ \\
\hline Lu 2013 [46] & $\begin{array}{l}\text { miRCURY } \\
\text { LNA Array } \\
\text { (Version } 16.0, \\
\text { Exiqon) }\end{array}$ & $\begin{array}{l}\text { Guangdong, } \\
\text { PR China }\end{array}$ & 1891 & plasma & 294TP & $109 \mathrm{NP}$ & $\mathrm{FC}>1.5, P<0.05$ \\
\hline Sengupta 2008 [47] & $\begin{array}{l}\text { Affymetrix HG } \\
\text { U133 Plus } 2.0 \\
\text { microarrays }\end{array}$ & $\begin{array}{l}\text { Taiwan, } \\
\text { Republic of } \\
\text { China }\end{array}$ & 207 & tissues & $55 \mathrm{TT}$ & $6 \mathrm{NC}$ & $\mathrm{FC}>1.5$ \\
\hline Tang 2014 [48] & $\begin{array}{l}\text { miRNA } \\
\text { microarray }\end{array}$ & $\begin{array}{l}\text { Guangdong, } \\
\text { PR China }\end{array}$ & 2047 & tissues & $3 \mathrm{TT}$ & $3 \mathrm{NC}$ & $\mathrm{FC} \geq 2, P<0.05$ \\
\hline Wang 2014 [9] & $\begin{array}{l}\text { Illumina/HiSeq } \\
2000 \text { platform }\end{array}$ & $\begin{array}{l}\text { Guangdong, } \\
\text { PR China }\end{array}$ & 1711 & plasma & $50 \mathrm{TP}$ & $50 \mathrm{NP}$ & $\mathrm{FC}>2, P<0.05$ \\
\hline $\mathrm{Xu} 2015$ [49] & $\begin{array}{l}\text { miRNA } \\
\text { microarray }\end{array}$ & $\begin{array}{l}\text { Guangdong, } \\
\text { PR China }\end{array}$ & 873 & tissues & $\begin{array}{l}330 \mathrm{TT}(312 \\
\text { paraffin- } \\
\text { embedded } \\
\text { and } 18 \\
\text { fresh- } \\
\text { frozen) }\end{array}$ & $\begin{array}{l}\text { 32NC(18 } \\
\text { paraffin- } \\
\text { embedded } \\
\text { and } 14 \\
\text { fresh- } \\
\text { frozen) }\end{array}$ & $P<0.05$ \\
\hline Zheng 2014 [10] & $\begin{array}{l}\text { miRNA } \\
\text { microarray }\end{array}$ & $\begin{array}{l}\text { Guangdong, } \\
\text { PR China }\end{array}$ & 937 & plasma & $31 \mathrm{TP}$ & $19 \mathrm{NP}$ & $\mathrm{FC}>2, P<0.05$ \\
\hline
\end{tabular}

Note: $\mathrm{TT}=$ tumor tissues, $\mathrm{ANT}=$ adjacent nontumorous tissues, $\mathrm{NT}=$ normal tissues, $\mathrm{TP}=$ tumor plasma, $\mathrm{NP}=$ normal plasma, $\mathrm{FC}=$ fold change.

\section{The enrichment analysis for predicted target of meta-signature miRNAs}

The enrichment analysis was completed by the DAVID web tool for predicted targets of meta-miRNAs. A lot of significant results were screened through the enrichment of KEGG, BioCarta and Panther pathways, most of which were associated with cell signaling, cell regulation and cancer, as shown in Table 3.

\section{DISCUSSION}

MiRNAs were considered as promising biomarkers for cancer detection at early stage and accurate prognosis after medical therapy. But the profiles of miRNAs always showed the inconsistent results in these studies. The following factors might be the possible reasons: 1 . the different platforms of profiling; 2. relatively small sample size and novel discovered miRNAs; 3 . inconsistent methods for data analysis. To overcome these defects, a meta-study using robust rank aggregation (RRA) method was performed for analysis of nasopharyngeal cancer particular miRNAs from eight independent profiling experiments. In comparison with classical vote-counting method, the RRA algorithm has four advantages: 1 . robust to noise; 2 . incomplete rankings; 3 . assign score to each element for ranking; 4. efficient to compute [14]. Furthermore, there has been a research focused on the comparison of two different meta-analysis methods about miRNAs different expression in pancreatic ductal adenocarcinoma. In this research, both results of different methods included the potential prognostic biomarkers, which were detected by experimental validation. But the RRA method was a little more accurate than vote-counting method [15].

Through this research, we found seven consensus significantly dysregulated miRNAs with three increased and four decreased expression in these studies $(p<0.05)$. Althrough none of these dysregulated miRNAs has passed the Conservative Bonferroni method correction, it is still meaningful for the future research. Especially, the cluster located at $1 \mathrm{q} 32.2$ 
Table 2: Meta-signature miRNAs in NPC

\begin{tabular}{|c|c|c|c|c|}
\hline MiRNA & Permutation $p$-value & Corrected $p$-value & No. of studies & Chromosome \\
\hline \multicolumn{5}{|l|}{ Upregulated } \\
\hline hsa-miR-483-5p & $8.828879 \mathrm{e}-05$ & $1.807272 \mathrm{e}-01$ & 3 & $11 \mathrm{p} 15.5$ \\
\hline hsa-miR-29c-3p & $1.845994 \mathrm{e}-03$ & $3.778750 \mathrm{e}+00$ & 3 & $1 \mathrm{q} 32.2$ \\
\hline hsa-miR-205-5p & $1.951966 \mathrm{e}^{-03}$ & $3.995674 \mathrm{e}+00$ & 3 & $1 \mathrm{q} 32.2$ \\
\hline \multicolumn{5}{|l|}{ Downregulated } \\
\hline hsa-miR-29b-3p & $1.861229 \mathrm{e}-04$ & $3.809936 \mathrm{e}-01$ & 5 & $1 \mathrm{q} 32.2$ \\
\hline hsa-let-7d-5p & $2.881485 \mathrm{e}^{-03}$ & $5.898400 \mathrm{e}+00$ & 3 & $9 q 22.32$ \\
\hline hsa-miR-100-5p & $3.345351 \mathrm{e}^{-03}$ & $6.847933 \mathrm{e}+00$ & 3 & $11 \mathrm{q} 24.1$ \\
\hline hsa-let-7g-5p & $5.079891 \mathrm{e}-03$ & $1.039854 \mathrm{e}+01$ & 3 & $3 \mathrm{p} 21.1$ \\
\hline
\end{tabular}

contained three dysregulated miRNAs: miR-29b-3p, miR-29c-3p, miR-205-5p. The following reasons may explain the limition in this research: 1. The Conservative Bonferroni correction is a very strict significant analysis method 2. there was still insuffcient independent experiments for analysis 3 . the sample size for miRNAs profiling was relatively small.
MiR-29b-3p and miR-29c-3p belong to the miR-29 family. Recently, more and more research has indicated that miR-29 family correlated with the process of many kinds of tumours. Yuan et al. have found that miR-29b as a suppressor could inhibit the growth of colorectal cancer cells by binding IGIF1, an activator of PI3K/ Akt signaling [16]. In 2015, Qi et al. proved that the

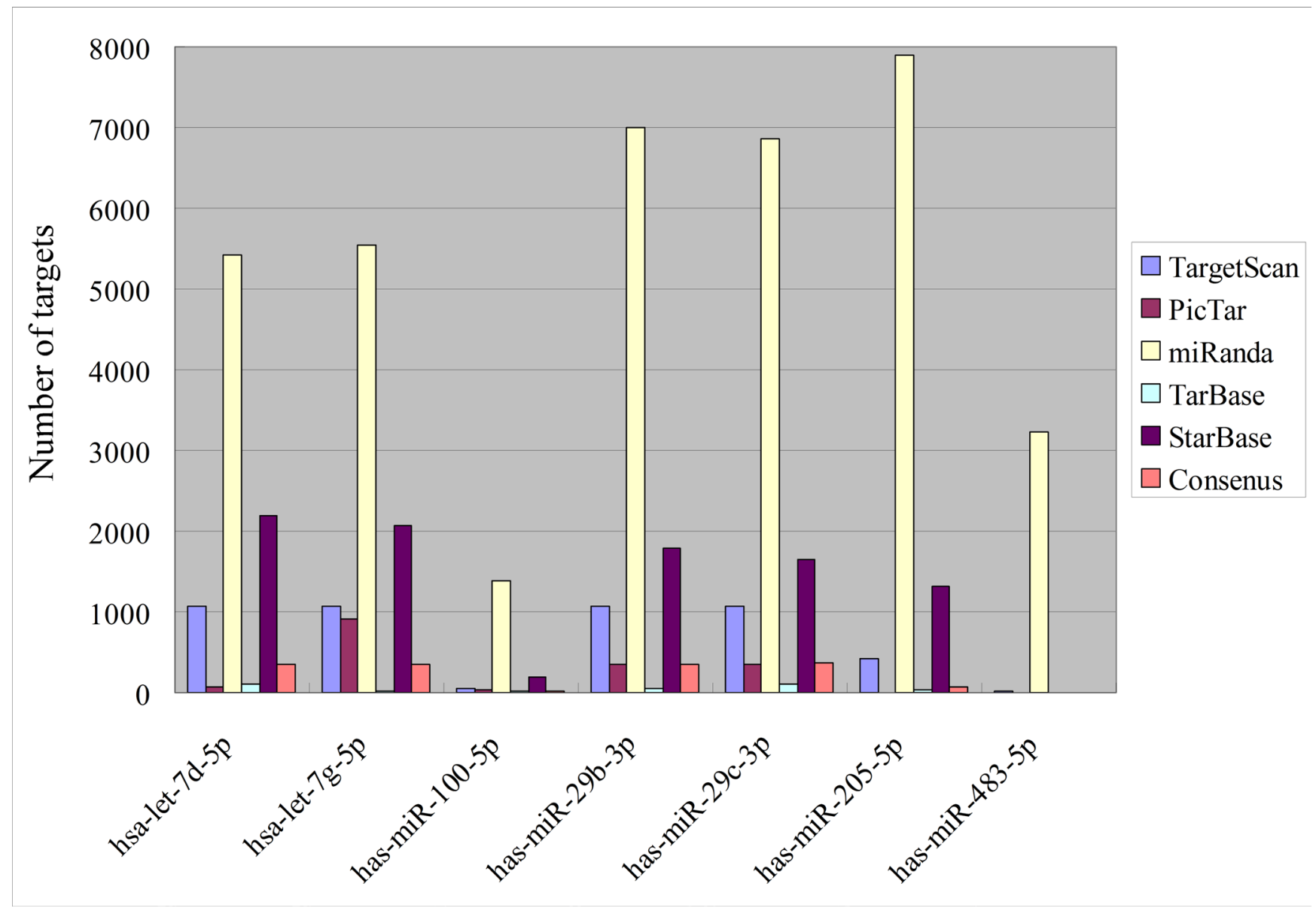

Figure 2: Target numbers of meta-signature miRNAs in NPC. 


\section{Table 3: GO process, KEGG Pathway, Panther pathway and REACTOME Pathway enriched by meta-signature miRNA targets}

\begin{tabular}{|c|c|c|}
\hline Pathway enrichment analysis & $P$-value & Targets \\
\hline \multicolumn{3}{|l|}{ GO process } \\
\hline GO:0010468:regulation of gene expression & $3.32262 \mathrm{E}-11$ & 182 \\
\hline GO:0060255:regulation of macromolecule metabolic process & $6.26409 \mathrm{E}-11$ & 200 \\
\hline GO:0010556:regulation of macromolecule biosynthetic process & $1.02846 \mathrm{E}-10$ & 179 \\
\hline GO:0019222:regulation of metabolic process & $2.92559 \mathrm{E}-10$ & 214 \\
\hline GO:0031323:regulation of cellular metabolic process & $8.60126 \mathrm{E}-10$ & 205 \\
\hline GO:0080090:regulation of primary metabolic process & $8.88383 \mathrm{E}-10$ & 197 \\
\hline GO:0009889:regulation of biosynthetic process & $1.49881 \mathrm{E}-9$ & 181 \\
\hline GO:0031326:regulation of cellular biosynthetic process & $2.81697 \mathrm{E}-9$ & 179 \\
\hline GO:0010608:posttranscriptional regulation of gene expression & $7.88979 \mathrm{E}-9$ & 30 \\
\hline GO:0044260:cellular macromolecule metabolic process & $7.53946 \mathrm{E}-8$ & 273 \\
\hline \multicolumn{3}{|l|}{ KEGG Pathway } \\
\hline 04510:Focal adhesion & $2.40574 \mathrm{E}-5$ & 22 \\
\hline 04512:ECM-receptor interaction & $7.55414 \mathrm{E}-5$ & 13 \\
\hline 05200:Pathways in cancer & $1.20000 \mathrm{E}-4$ & 28 \\
\hline 05214:Glioma & $6.07598 \mathrm{E}-4$ & 10 \\
\hline 05210:Colorectal cancer & $1.31904 \mathrm{E}-3$ & 11 \\
\hline 05222:Small cell lung cancer & $4.70774 \mathrm{E}-3$ & 10 \\
\hline 05212:Pancreatic cancer & $6.08526 \mathrm{E}-3$ & 9 \\
\hline 00310:Lysine degradation & $6.31374 \mathrm{E}-3$ & 7 \\
\hline 05215:Prostate cancer & $6.89094 \mathrm{E}-3$ & 10 \\
\hline 04520:Adherens junction & $9.08516 \mathrm{E}-3$ & 9 \\
\hline \multicolumn{3}{|l|}{ Panther Pathways } \\
\hline P00034:Integrin signalling pathway & $8.30518 \mathrm{E}-4$ & 22 \\
\hline P04398:p53 pathway feedback loops & $6.41257 \mathrm{E}-3$ & 7 \\
\hline P00030:Hypoxia response via HIF activation & $7.53552 \mathrm{E}-3$ & 5 \\
\hline \multicolumn{3}{|l|}{ REACTOME Pathway } \\
\hline REACT_16888:Signaling by PDGF & $5.61551 \mathrm{E}-7$ & 14 \\
\hline REACT_18266:Axon guidance & $1.17314 \mathrm{E}-5$ & 11 \\
\hline REACT_13552:Integrin cell surface interactions & $2.21768 \mathrm{E}-4$ & 12 \\
\hline REACT_498:Signaling by Insulin receptor & $3.34885 \mathrm{E}-3$ & 7 \\
\hline
\end{tabular}

overexpression of miR-29b significantly reduced the protein of MMP-2 which suppressed the cell invasion of esophageal squamous cell carcinoma [17]. Meanwhile, the miR-29b was suggested to inhibit the migration and invasion of nasopharyngeal carcinoma cell lines in vitro [18]. Recent study showed that the overexpression of miR-29c can suppress pancreatic cancer liver metastasis in nude mice and was associated with survival of pancreatic cancer patient [19]. In our meta-analysis, miR-205-5p was significantly increased in NPC, which is located at 1q32.2 with miR-29b-3p and miR-29c-3p. The overexpression of miR-205 was demonstrated to induce the expression of the tumor suppressor genes in prostate cancer [20]. The upregulation of miR-205 could also stimulate keratinocyte migration, specifically, which might be a marker for cutaneous squamous cell carcinoma [21]. Moreover, through the association analysis of human embryonic stem cell line $\mathrm{H} 1$, a large $5 \mathrm{Mb}$ duplication in chromosome 1q32.2 was detected to be associated with the genes with known roles in cancer [22]. These results suggest that miR-29b$3 p$, miR-29c-3p and miR-205-5p included in the cluster at 1q32.2 were potential molecular markers for diagnostics, therapeutics and prognosis of carcinomas. It is important for further investigation of these miRNAs in NPC. 
MiR-Let-7 family had correlation with the occurrence and development of many kinds of carcinomas, such as lung cancer, breast cancer, colorectal cancer and so on [23-25]. In this research, let-7d and let-7g were significantly decreased in the NPC tumor tissue, which was the same with the traditional meta-analysis about head and neck carcinoma [26]. The results indicate that these two miRNA may be the key components in progression of NPC and the RRA method has pretty good repetitive in gene expression analysis compared with traditional method of meta-analysis. MiR-483-5p is a relatively new discovered miRNA, there was little information about this miRNA in target prediction and pathway enrichment analysis through web tools. The significant up-regulation of miR-483-5p was proved closely relating with the progression of lung adenocarcinoma and multiple myeloma $[27,28]$. MiR-100 was significantly decreased in our meta-analysis, which was also found consistently negatively correlated with the head and neck carcinoma by other systematic analysis [29]. This is supported by our analysis that miR-100 is an important regulatory molecule in the progression of NPC.

It was found that the microRNAs had prognostic value and was closely correlated with survival time for cancer patients in previous studies. In 2012, the miRNA expression profiles of 330 specimens of nasopharyngeal carcinoma was analysed and the miR-29c-3p was found to be positive with the disease-free survival [30]. The decreased expression of miR-205-5p, let-7d-5p and let$7 \mathrm{~g}-5 \mathrm{p}$ was proved significantly associated with survival of head and neck cancer patients $[31,32]$. The miR-483-5p in the serum was proved to be an independent prognosis factor for head and neck carcinoma [33]. The miR-100 and miR-29b-3p were also found to be a prognosis factor of non-head and neck carcinoma patients [34, 35]. It suggests that these significant miRNAs have great value for the clinical diagnosis, prognosis and treatment.

From the pathway enrichment analysis, we found that many signaling pathways were involved in the regulation of miRNAs, for example, integrin signaling pathway, signaling pathways by PDGF and insulin receptor (Table 3 ). Through the KEGG pathway analysis (Table 3), we saw that the focal adhesion kinase (FAK) pathway was the most significantly related pathway, which was highly correlated with the invasion of head and neck carcinoma cell lines [36], especially the differentiation and metastases in nasopharyngeal carcinoma [37]. Many other cancer pathway targets were also enriched, for example, colorectal cancer, small cell lung cancer, prostate cancer, etc. The regulation of miRNA in different cancers may have the same overlapping target genes. It may suggest that miRNAs could bring us key information and insight into cancer therapy.

In total, we have identified 7 highly significant dysregulated miRNAs across 8 independent studies in NPC. The meta-signature miRNAs and related pathways may be promising markers for clinical intervention. The further investigation should still focus on the molecular mechanisms that miRNAs may exert in the occurrence, progression and metastasis of NPC.

\section{MATERIALS AND METHODS}

\section{Search strategies}

A two-step literature searching strategy was used to identify the nasopharyngeal carcinoma miRNA expression profiling studies. First of all, the Pubmed database, Gene Expression Omnibus (GEO, www.ncbi.nlm.-nih.gov/ geo/), and ArrayExpress (www.ebi.ac.uk/arrayexpress) were performed research according to the subsequent criteria: (microRNA OR miRNA) AND (nasopharyngeal carcinoma OR nasopharyngeal cancer OR nasopharyngeal tumor OR nasopharyngeal neoplasm) AND (expression OR profile OR profiling); and then, the relevant references, which had been in accordance with the criteria above mentioned, were carefully screened through manual search for further potential studies. The latest search was performed on April 22, 2015.

\section{Study selection}

The abstracts and key words of the articles were carefully checked, and the whole text of which was appraised. Only original experiments published in English about nasopharyngeal cancer miRNA expression profiling in human were included. At the same time, studies were excluded for this meta-analysis as they met the following criteria: (1) only cell lines of nasopharyngeal carcinoma were used in the experimental design; (2) preselected candidate miRNAs research; (3) using RT-PCR only for profiling studies; (4) studies without noncancerous controls; (5) Cut- off criteria not reported of miRNA expression; (6) review literature, and case reports.

\section{Data extraction}

There are two investigators (Junwen Luan AND Junfu Wang) evaluated and collected the profiling information using protocols above. According to the full article and Supplementary Materials of each selected study, the following items were extracted: author, period of publication, location, selection and characteristics of recruited NPC patients, platform of miRNA expressed profiling, sample size, tissue types, cut-off criteria and fold change of dysregulated miRNA. If the gene list was not included in the full text and supplementary information, for which we would then directly contact the authors. All of the miRNA names were standardized depending on the miRBase (www.mirbase.org, version 21). We omitted the miRNAs that were "dead entry" due to re-annotation at present miRBase in subsequent meta-analysis. 


\section{Robust rank aggregation method for meta- analysis}

Robust rank aggregation method (RRA) is a free package of $\mathrm{R}$ software, which was used for this metaanalysis. The RRA package can be downloaded at the R Archive Network website (http://cran.R-project.org/), and the guidelines could be found in the package documents (http://cran.r-project.org/web/packages/RobustRankAggreg/ RobustRankAggreg.pdf).

All of the gene lists of miRNAs from selected articles were ranked according to their the $P$-values $(p<0.05)$ without fold-changes information by RRA method. The leave-one-out cross-validation algorithm was applied in this method. A ten thousand times repeating analysis was carried out to calculate an average $p$-values from random gene lists, which can represent the best $p$-value of each miRNAs. To avoid the false positive results, Bonferroni correction of $P$-value was calculated.

\section{Prediction and filtering of dysregulated miRNAs targets}

The targets of miRNA were predicted by TargetScan v6.2 [38] (www.targetscan.org), PicTar [39] (http://pictar. mdc-berlin.de/), and miRDB [40] (http://mirdb.org/ miRDB/). TarBase v7.0 database [41] and starBase [42] were also screened to provide experimental proof for predicted targets. For the accuracy of study, overlapping targets, which were predicted more than one algorithm were selected for further study.

\section{Enrichment analysis}

To carry out the enrichment analysis, the DAVID web tool $[43,44]$ (http://david.abcc.ncifcrf.gov/) were used for pathways identification and enrichment analysis. The consensus targets of each miRNA were as input to screen the following database Gene Ontology terms, KEGG, Panther and REACTOME pathways.

\section{ACKNOWLEDGMENTS}

We thank Mr. Xing Chen, Meng Luan and Peng Zhou for their help on retrieval network.

\section{GRANT SUPPORT}

The present study was supported by grants from the National Natural Science Foundation of China (no. 81202314, 81172792, 81573467), the Natural Science Foundation of Shandong Province (no. ZR2013HL028, ZR2015YL028, ZR2015PC018, 2015ZRC03102) and the medical and health technology development program of Shandong province (no. 2014WS0314), the 'Twelfth Five-Year' National Science and Technology Support Program (2013BAI07B02) and the Project for Laureate of Taishan Scholar (NO.ts201511075).

\section{CONFLICTS OF INTEREST}

The authors declare that they have no competing interests.

\section{REFERENCE}

1. Lo KW, To KF, Huang DP. Focus on nasopharyngeal carcinoma. Cancer cell. 2004; 5:423-428.

2. Torre LA, Bray F, Siegel RL, Ferlay J, Lortet-Tieulent J, Jemal A. Global cancer statistics, 2012. CA Cancer J Clin. 2015; 65:87-108.

3. Bartel DP. MicroRNAs: genomics, biogenesis, mechanism, and function. Cell. 2004; 116:281-297.

4. Lee HK, Finniss S, Cazacu S, Bucris E, Ziv-Av A, Xiang C, Bobbitt K, Rempel SA, Hasselbach L, Mikkelsen T, Slavin S, Brodie C. Mesenchymal stem cells deliver synthetic microRNA mimics to glioma cells and glioma stem cells and inhibit their cell migration and self-renewal. Oncotarget. 2013; 4:346-361. doi: 10.18632/oncotarget.868.

5. Calin GA, Ferracin M, Cimmino A, Di Leva G, Shimizu M, Wojcik SE, Iorio MV, Visone R, Sever NI, Fabbri M, Iuliano R, Palumbo T, Pichiorri F, et al. A MicroRNA signature associated with prognosis and progression in chronic lymphocytic leukemia. The New England journal of medicine. 2005; 353:1793-1801.

6. Cho WC. MicroRNAs: potential biomarkers for cancer diagnosis, prognosis and targets for therapy. Int J Biochem Cell Biol. 2010; 42:1273-1281.

7. Kavitha N, Vijayarathna S, Jothy SL, Oon CE, Chen Y, Kanwar JR, Sasidharan S. MicroRNAs: biogenesis, roles for carcinogenesis and as potential biomarkers for cancer diagnosis and prognosis. Asian Pacific journal of cancer prevention. 2014; 15:7489-7497.

8. Schetter AJ, Leung SY, Sohn JJ, Zanetti KA, Bowman ED, Yanaihara N, Yuen ST, Chan TL, Kwong DL, Au GK, Liu CG, Calin GA, Croce CM, et al. MicroRNA expression profiles associated with prognosis and therapeutic outcome in colon adenocarcinoma. JAMA. 2008; 299:425-436.

9. Wang HY, Yan LX, Shao Q, Fu S, Zhang ZC, Ye W, Zeng YX, Shao JY. Profiling plasma microRNA in nasopharyngeal carcinoma with deep sequencing. Clinical Chemistry. 2014; 60:773-782.

10. Zheng XH, Cui C, Ruan HL, Xue WQ, Zhang SD, Hu YZ, Zhou XX, Jia WH. Plasma microRNA profiling in nasopharyngeal carcinoma patients reveals miR-548q and miR-483-5p as potential biomarkers. Chinese journal of cancer. 2014; 33:330-338. 
11. Li T, Chen JX, Fu XP, Yang S, Zhang Z, Chen Kh H, Li Y. microRNA expression profiling of nasopharyngeal carcinoma. Oncology reports. 2011; 25:1353-1363.

12. Ryu S, Joshi N, McDonnell K, Woo J, Choi H, Gao D, McCombie WR, Mittal V. Discovery of novel human breast cancer microRNAs from deep sequencing data by analysis of pri-microRNA secondary structures. PloS one. 2011; 6:e16403.

13. Yanaihara N, Caplen N, Bowman E, Seike M, Kumamoto K, Yi M, Stephens RM, Okamoto A, Yokota J, Tanaka T, Calin GA, Liu CG, Croce CM, et al. Unique microRNA molecular profiles in lung cancer diagnosis and prognosis. Cancer cell. 2006; 9:189-198.

14. Kolde R, Laur S, Adler P, Vilo J. Robust rank aggregation for gene list integration and meta-analysis. Bioinformatics. 2012; 28:573-580.

15. Ma MZ, Kong X, Weng MZ, Cheng K, Gong W, Quan ZW, Peng CH. Candidate microRNA biomarkers of pancreatic ductal adenocarcinoma: meta-analysis, experimental validation and clinical significance. Journal of experimental \& clinical cancer research. 2013; 32:71.

16. Yuan L, Zhou C, Lu Y, Hong M, Zhang Z, Zhang Z, Chang Y, Zhang C, Li X. IFN-gamma-mediated IRF1/miR$29 \mathrm{~b}$ feedback loop suppresses colorectal cancer cell growth and metastasis by repressing IGF1. Cancer letters. 2015; 359:136-147.

17. Qi Y, Li X, Zhao S. miR-29b inhibits the progression of esophageal squamous cell carcinoma by targeting MMP-2. Neoplasma. 2015; 62:384-390.

18. Qiu F, Sun R, Deng N, Guo T, Cao Y, Yu Y, Wang X, Zou B, Zhang S, Jing T, Ling T, Xie J, Zhang Q. miR-29a/b enhances cell migration and invasion in nasopharyngeal carcinoma progression by regulating SPARC and COL3A1 gene expression. PloS one. 2015; 10:e0120969.

19. Zou Y, Li J, Chen Z, Li X, Zheng S, Yi D, Zhong A, Chen J. miR-29c suppresses pancreatic cancer liver metastasis in an orthotopic implantation model in nude mice and affects survival in pancreatic cancer patients. Carcinogenesis. 2015; 36:676-684.

20. Majid S, Dar AA, Saini S, Yamamura S, Hirata H, Tanaka Y, Deng G, Dahiya R. MicroRNA-205-directed transcriptional activation of tumor suppressor genes in prostate cancer. Cancer. 2010; 116:5637-5649.

21. Bruegger C, Kempf W, Spoerri I, Arnold AW, Itin PH, Burger B. MicroRNA expression differs in cutaneous squamous cell carcinomas and healthy skin of immunocompetent individuals. Experimental dermatology. 2013; 22:426-428.

22. Hovatta O, Jaconi M, Tohonen V, Bena F, Gimelli S, Bosman A, Holm F, Wyder S, Zdobnov EM, Irion O, Andrews PW, Antonarakis SE, Zucchelli M, et al. A teratocarcinoma-like human embryonic stem cell (hESC) line and four hESC lines reveal potentially oncogenic genomic changes. PloS one. 2010; 5:e10263.

23. Oztemur Y, Bekmez T, Aydos A, Yulug IG, Bozkurt B, Dedeoglu BG. A ranking-based meta-analysis reveals let-7 family as a meta-signature for grade classification in breast cancer. PloS one. 2015; 10:e126837.

24. Wang J, Huang SK, Zhao M, Yang M, Zhong JL, Gu YY, Peng H, Che YQ, Huang CZ. Identification of a circulating microRNA signature for colorectal cancer detection. PloS one. 2014; 9:e87451.

25. Shen LQ, Xie YZ, Qian XF, Zhuang ZX, Jiao Y, Qi XF. A single nucleotide polymorphism in the promoter region of let-7 family is associated with lung cancer risk in Chinese. Genetics and molecular research. 2015; 14:4505-4512.

26. Jamali Z, Asl Aminabadi N, Attaran R, Pournagiazar F, Ghertasi Oskouei S, Ahmadpour F. MicroRNAs as prognostic molecular signatures in human head and neck squamous cell carcinoma: a systematic review and metaanalysis. Oral oncology. 2015; 51:321-331.

27. Qu X, Zhao M, Wu S, Yu W, Xu J, Xu J, Li J, Chen L. Circulating microRNA 483-5p as a novel biomarker for diagnosis survival prediction in multiple myeloma. Medical oncology. 2014; 31:219.

28. Song Q, Xu Y, Yang C, Chen Z, Jia C, Chen J, Zhang Y, Lai P, Fan X, Zhou X, Lin J, Li M, Ma W, et al. miR-483-5p promotes invasion and metastasis of lung adenocarcinoma by targeting RhoGDI1 and ALCAM. Cancer research. 2014; 74:3031-3042.

29. Chen D, Cabay RJ, Jin Y, Wang A, Lu Y, Shah-Khan M, Zhou X. MicroRNA Deregulations in Head and Neck Squamous Cell Carcinomas. Journal of oral \& maxillofacial research. 2013; 4:e2.

30. Liu N, Chen NY, Cui RX, Li WF, Li Y, Wei RR, Zhang MY, Sun Y, Huang BJ, Chen M, He QM, Jiang N, Chen L, et al. Prognostic value of a microRNA signature in nasopharyngeal carcinoma: a microRNA expression analysis. The Lancet Oncology. 2012; 13:633-641.

31. Peng SC, Liao CT, Peng $\mathrm{CH}$, Cheng AJ, Chen SJ, Huang CG, Hsieh WP, Yen TC. MicroRNAs MiR-218, MiR-125b, and Let- $7 \mathrm{~g}$ predict prognosis in patients with oral cavity squamous cell carcinoma. PloS one. 2014; 9:e102403.

32. Childs G, Fazzari M, Kung G, Kawachi N, BrandweinGensler M, McLemore M, Chen Q, Burk RD, Smith RV, Prystowsky MB, Belbin TJ, Schlecht NF. Low-level expression of microRNAs let-7d and miR-205 are prognostic markers of head and neck squamous cell carcinoma. The American journal of pathology. 2009; 174:736-745.

33. Xu H, Yang Y, Zhao H, Yang X, Luo Y, Ren Y, Liu W, Li N. Serum miR-483-5p: a novel diagnostic and prognostic biomarker for patients with oral squamous cell carcinoma. Tumour biology. 2015. PMID: 26224475.

34. Cao YH, Zhang HH, Xu HF, Duan YJ, Li Q, Huang B. Prognostic role of microRNA-100 in patients with bladder cancer. Genetics and molecular research. 2015; 14: 15948-15954.

35. Bahador R, Taheriazam A, Mirghasemi A, Torkaman A, Shakeri M, Yahaghi E, Goudarzi PK. Tissue expression levels of miR-29b and miR-422a in children, adolescents, and young adults' age groups and their association with 
prediction of poor prognosis in human osteosarcoma. Tumour biology. 2015. PMID: 26423405.

36. Ou J, Pan F, Geng P, Wei X, Xie G, Deng J, Pang X, Liang $\mathrm{H}$. Silencing fibronectin extra domain A enhances radiosensitivity in nasopharyngeal carcinomas involving an FAK/Akt/JNK pathway. International journal of radiation oncology, biology, physics. 2012; 82:e685-691.

37. Canel M, Secades P, Garzon-Arango M, Allonca E, Suarez C, Serrels A, Frame M, Brunton V, Chiara MD. Involvement of focal adhesion kinase in cellular invasion of head and neck squamous cell carcinomas via regulation of MMP-2 expression. Br J Cancer. 2008; 98:1274-1284.

38. Grimson A, Farh KK, Johnston WK, Garrett-Engele P, Lim LP, Bartel DP. MicroRNA targeting specificity in mammals: determinants beyond seed pairing. Molecular cell. 2007; 27:91-105.

39. Blin K, Dieterich C, Wurmus R, Rajewsky N, Landthaler M, Akalin A. DoRiNA 2.0-upgrading the doRiNA database of RNA interactions in post-transcriptional regulation. Nucleic acids research. 2015; 43(Database issue):D160-167.

40. Wong N, Wang X. miRDB: an online resource for microRNA target prediction and functional annotations. Nucleic acids research. 2015; 43:D146-152.

41. Vlachos IS, Paraskevopoulou MD, Karagkouni D, Georgakilas G, Vergoulis T, Kanellos I, Anastasopoulos IL, Maniou S, Karathanou K, Kalfakakou D, Fevgas A, Dalamagas T, Hatzigeorgiou AG. DIANA-TarBase v7.0: indexing more than half a million experimentally supported miRNA:mRNA interactions. Nucleic acids research. 2015; 43:D153-159.

42. Yang JH, Li JH, Shao P, Zhou H, Chen YQ, Qu LH. starBase: a database for exploring microRNA-mRNA interaction maps from Argonaute CLIP-Seq and Degradome-Seq data. Nucleic acids research. 2011; 39:D202-209.

43. Huang da W, Sherman BT, Lempicki RA. Bioinformatics enrichment tools: paths toward the comprehensive functional analysis of large gene lists. Nucleic acids research. 2009; 37:1-13.
44. Huang da W, Sherman BT, Lempicki RA. Systematic and integrative analysis of large gene lists using DAVID bioinformatics resources. Nature protocols. 2009; 4:44-57.

45. Plieskatt JL, Rinaldi G, Feng Y, Levine PH, Easley S, Martinez E, Hashmi S, Sadeghi N, Brindley PJ, Bethony JM, Mulvenna JP. Methods and matrices: approaches to identifying miRNAs for nasopharyngeal carcinoma. Journal of Translational Medicine. 2014; 12:3.

46. Lu J, Xu X, Liu X, Peng Y, Zhang B, Wang L, Luo H, Peng X, Li G, Tian W, He M, Li X. Predictive value of miR-9 as a potential biomarker for nasopharyngeal carcinoma metastasis. British Journal of Cancer. 2013; 110:392-398.

47. Sengupta S, den Boon JA, Chen IH, Newton MA, Stanhope SA, Cheng YJ, Chen CJ, Hildesheim A, Sugden B, Ahlquist P. MicroRNA 29c is down-regulated in nasopharyngeal carcinomas, up-regulating mRNAs encoding extracellular matrix proteins. Proceedings of the National Academy of Sciences of the United States of America. 2008; 105:5874-5878.

48. Tang J-F, Yu Z-H, Liu T, Lin Z-Y, Wang Y-H, Yang L-W, He H-J, Cao J, Huang H-L, Liu G. Five miRNAs as Novel Diagnostic Biomarker Candidates for Primary Nasopharyngeal Carcinoma. Asian Pacific Journal of Cancer Prevention. 2014; 15:7575-7581.

49. Xu Y-F, Li Y-Q, Guo R, He Q-M, Ren X-Y, Tang X-R, Jia W-H, Kang T-B, Zeng M-S, Sun Y, Ma J, Liu N. Identification of miR-143 as a tumour suppressor in nasopharyngeal carcinoma based on microRNA expression profiling. The International Journal of Biochemistry \& Cell Biology. 2015; 61:120-128.V 